\title{
Endogenous lithium clearance: a diagnostic method of assessing sodium sensitivity in hypertension. Methodological and clinical implications
}

\author{
Marcin Cwynar ${ }^{1}$, Tomasz Stompór ${ }^{2}$, Henryk Bartoń ${ }^{3}$, Tomasz Grodzicki ${ }^{1}$ \\ 'Department of Internal Medicine and Gerontology, Medical College, Jagiellonian University, Krakow, Poland \\ 2Department of Nephrology, Hypertension and Internal Diseases, Chair of Internal Diseases, Faculty of Medicine, \\ University of Warmia and Mazury, Olsztyn, Poland \\ ${ }^{3}$ Trace Element Research Laboratory, Department of Food Chemistry and Nutrition, Faculty of Pharmacy, Medical College, \\ Jagiellonian University, Krakow, Poland
}

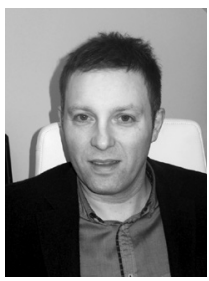

INTRODUCTION

Excessive dietary sodium intake is known to be the most important factor contributing to the development of hypertension. Daily sodium requirement is approximately $0.5 \mathrm{~g}$, and maximum recommended daily intake is $1.5 \mathrm{~g}$, corresponding to $3.8 \mathrm{~g}$ of salt [1]. The

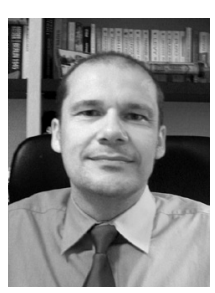
contribution of sodium to the pathogenesis of hypertension is primarily related to the phenomenon of sodium sensitivity. Its prevalence in the general Caucasian population is estimated at 20\% but it approaches $50 \%$ in patients with hypertension. It is even more prevalent in South-Asian and African populations. Sodium sensitivity is closely related to

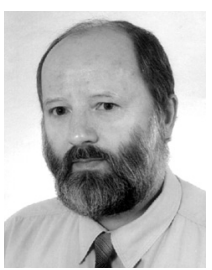
the efficiency of renal mechanisms of sodium excretion, referred to as pressure natriuresis, which ultimately results in increased glomerular filtration rates (GFR) and inhibition of sodium and water reabsorption in renal tubules. Thus, elevated blood pressure (BP) associated with increased sodium intake is related to an impairment of the mechanisms that allow for increasing urinary sodium excretion per time unit [2].

One of the diagnostic methods of assessing sodium sensitivity of hypertension that has been known for many years and is currently increasingly applied in the research on sodium sensitivity is the measurement of sodium reabsorption in proximal and distal renal tubules using endogenous lithium clearance.

\section{THE ROLE OF SODIUM}

IN THE PATHOGENESIS OF HYPERTENSION

In the populations of developed countries where the prevalence of hypertension is markedly higher than in developing countries, significant differences in the amounts of salt consumed in the diet have been observed. The INTERSALT study was the largest clinical trial which evaluated, among other parameters, salt intakes in various populations. It was conducted in 32 countries worldwide and included over 10,000 adults aged from 20 to 59 years. A standardised method of assessment of daily sodium and potassium urinary excretion was used in all participating centres. Sodium excretion varied markedly in respective groups and ranged from $0.2 \mathrm{mmol} /$ day to $242 \mathrm{mmol} /$ day, thus indicating a substantial heterogeneity of the investigated populations [3].

Data on the deleterious effects of excess salt intake on the pathogenesis of hypertension comes from animal models and epidemiological studies. In chimpanzees fed with a very low-sodium and low-potassium vegetarian diet, an increase of dietary sodium to 10-15 g/day for 20 months was associated with a $33 \mathrm{~mm} \mathrm{Hg}$ elevation of systolic blood pressure (SBP) [4]. Results of epidemiological studies also clearly indicated a positive correlation of sodium intake and SBP (but not diastolic blood pressure [DBP]) [5, 6]. Moreover, du Cailar et al. [7] demonstrated an independent correlation of increased sodium intake and elevated pulse pressure. On the other hand, a reduction of sodium intake results in lowering SBP

Address for correspondence:

Marcin Cwynar, MD, PhD, Department of Internal Medicine and Gerontology, Medical College, Jagiellonian University, ul. Śniadeckich 10, 31-351 Kraków, Poland, tel: +48 1242111 93, fax: +48 1242310 80, e-mail: marcincw@poczta.onet.pl

Copyright (C) Polskie Towarzystwo Kardiologiczne 
and pulse pressure, particularly in elderly patients with isolated systolic hypertension [6]. A meta-analysis of 56 clinical trials published in 1998 by Graudal et al. [8] revealed that reduction of sodium intake (defined on the basis of reduction of urinary sodium excretion by $100 \mathrm{mmol} / \mathrm{L}$ ) in hypertensive subjects was associated with a statistically significant $3.7 \mathrm{~mm}$ Hg decrease of SBP and $0.9 \mathrm{~mm} \mathrm{Hg}$ decrease of DBP. In normotensive subjects, the effect was significant only for SBP. The effects of diet on BP were also assessed in the DASH study (Dietary Approaches to Stop Hypertension) [9] and the TOHP study (The Trials of Hypertension Prevention) [10]. These studies demonstrated unequivocally that in order to decrease BP, it is necessary to reduce salt intake as well as to reduce calorie intake by limiting the consumption of saturated fats.

For a long time it was presumed that increased serum sodium levels cause the elevation of BP only due to increased blood volume and peripheral resistance resulting from structural and functional changes of arterioles. However, recent basic science research and population surveys have provided abundant evidence proving that sodium may contribute to end-organ cardiovascular and renal complications mediated by mechanisms independent of BP [11]. Remodelling of the walls of large arteries observed both in animal models and in humans is associated mainly with increased thickness of the tunica media and quantitative and structural alterations of collagen and elastin. In a study on spontaneously hypertensive rats (SHR), Et-Taoui et al. [12] observed that a high-sodium diet caused reduced hyaluronate contents in the wall of aorta and hyperplasia of the tunica media, leading to reduction of compliance of the walls of large arteries that was independent of average BP and of alterations of collagen and elastin contents. Other studies on SHR have also revealed that increased dietary sodium intake was associated with vascular hypertrophy and remodelling which involved not only an increased tunica media thickness but also an elevated extracellular elastin and collagen contents in the aortal wall [13, 14]. In their pioneering study of a Chinese population, Avolio et al. [15] demonstrated that increased consumption of salt (13.3 g $\mathrm{NaCl} /$ day vs. $7.3 \mathrm{~g} \mathrm{NaCl} /$ day) was associated with significantly higher stiffness of the aortal wall measured using the pulse wave velocity method, regardless of the age and BP of the subjects. Other authors have also demonstrated a BP-independent influence of sodium on left ventricular hypertrophy [16] and impaired contractility of the left ventricle [17].

To date, the concept of sodium sensitivity of hypertension has been based on the traditional 'two-compartment' model (with intracellular sodium as one compartment and extracellular sodium as another broad compartment, with a presumed lack of differences of sodium concentrations between various extracellular fluid compartments). However, this concept was significantly modified on the basis of experimental and clinical research by Titze et al. [18]. The authors revealed that anionic glycosaminoglycans, located predominantly in the skin, are able to accumulate significant amounts of sodium ions without subsequent accumulation of water; this proves the presence of the third, hyperosmolar 'compartment' accumulating sodium. This compartment might be a very important 'buffer' to the hypertensive activity of excess sodium acting by binding the ions that might be later released again in cases of sodium deficiency. According to this concept, sodium dependence of hypertension might develop not only due to renal mechanisms regulating water and electrolyte homeostasis, but also due to defective binding of excess sodium by glycosaminoglycans of connective tissue (extrarenal regulation). The release or retention of sodium in this compartment would be controlled by the connective tissue monocyte/macrophage system regulating the effectiveness of lymphatic drainage by the secreted cytokines [18-20]. This mechanism is also an argument in the criticism of measuring sodium intake solely on the basis of its daily urinary excretion.

\section{ENDOGENOUS LITHIUM CLEARANCE: METHODOLOGY}

In clinical trials, several methods have been used for the evaluation of water and sodium turnover. Luft et al. [21] observed that in population studies, daily urinary sodium excretion is an adequate measure of dietary sodium intake. Nevertheless, 24-h urine collection is associated with a relatively high measurement bias, usually resulting from an inaccurate sample collection.

In recent years, 24-h endogenous lithium clearance has become a method allowing for accurate estimation of renal sodium reabsorption free of measurement bias. Lithium ions undergo filtration in renal glomeruli, while their reabsorption takes place mainly in proximal tubules simultaneously to the reabsorption of water and sodium. Early studies on tubular sodium reabsorption using the endogenous lithium clearance method were conducted in the 1980s. Initially they were based on the assessment of endogenous clearance of lithium administered in a form of carbonate [22]. Later, spectrophotometry was introduced in the methodology of the measurement of endogenous lithium clearance. This allowed for measuring sodium and water reabsorption without special preparation, based on the samples collected routinely for diagnostic tests. Lithium is naturally present in blood because of its wide presence in soil, water and foods, particularly vegetables and fruits. Serum levels of lithium vary in individual regions, and in persons without occupational or environmental exposure to excess levels of lithium, they range from 0.6 to $3.8 \mu \mathrm{g} / \mathrm{L}[23,24]$, although they may sometimes be well outside these values [25]. Urine lithium levels may be one order of magnitude higher.

The measurements of lithium clearance were based on the assumption that reabsorption of lithium takes place almost exclusively in proximal renal tubules, and that all the non-reabsorbed lithium ions are excreted with urine. Thus, 
the measurements of serum and urinary lithium levels allow for the estimation of fractional lithium excretion $\left(\mathrm{FE}_{\mathrm{L}}\right)$. Because the transport of lithium ions through cellular membranes of the proximal renal tubule cells involves the same cellular mechanisms as the transport of sodium and water, $\mathrm{FE}_{\mathrm{Li}}$ is a very accurate, glomerular filtration-dependent, marker of fractional sodium reabsorption in proximal tubules $\left(\mathrm{FE}_{\mathrm{Na}}\right)$. Thus, to calculate lithium and sodium reabsorption, it is necessary to assess six parameters: lithium concentration (sLi, uLi), sodium concentration (s $\mathrm{Na}, \mathrm{uNa}$ ) and creatinine concentration (sCR, uCR) in simultaneously collected serum and 24-h urine samples. Clearances are calculated as $C_{x}=U_{x} \times V / P_{x^{\prime}}$ where $U_{x}$ and $P_{x}$ are the urinary and serum concentrations of the solute $x^{\prime}$ and $V$ is the urine flow rate in millilitres per minute. High lithium clearance or a small difference between lithium and sodium clearances indicates a better ability to excrete sodium from the corresponding tubule, but does not depend on pressure natriuresis. The fractional excretion of sodium $\left(\mathrm{FE}_{\mathrm{Na}}\right)$ is calculated using the formula: $\mathrm{FE}_{\mathrm{Na}}=\mathrm{C}_{\mathrm{Na}}$ (sodium clearance) $/ C_{C R}$ (creatinine clearance) and the fractional excretion of lithium $\left(\mathrm{FE}_{\mathrm{Li}}\right)$ is calculated using an analogous formula: $\mathrm{FE}_{\mathrm{Li}}=\mathrm{C}_{\mathrm{Li}}$ (lithium clearance) $/ \mathrm{C}_{\mathrm{CR}}$ (creatinine clearance), and expressed as a percentage. $\mathrm{A}$ higher $\mathrm{FE}_{\mathrm{Li}}$ indicates that less sodium and water is reabsorbed in the proximal tubule and hence more sodium and water is cleared from the proximal tubule to the distal tubule [26].

The simultaneous calculations of $\mathrm{FE}_{\mathrm{Li}}$ and $\mathrm{FE}_{\mathrm{Na}}$ allow for the calculation of anestimated fractional distal sodium reabsorption $\left(\mathrm{RNa}_{\text {dist }}\right)$ according to the formula: $\mathrm{RNa}_{\text {dist }}=\left[\left(\mathrm{FE}_{\mathrm{Li}}-\mathrm{FE}_{\mathrm{Na}}\right) /\right.$ $\left./ \mathrm{FE}_{\mathrm{Li}}\right] \times 100 . \mathrm{RNa}_{\text {dist }}$ is an estimation of the amount of sodium that was not reabsorbed in proximal tubules, but its reabsorption took place in the distal renal tubules. Estimated fractional proximal sodium reabsorption $\left(\mathrm{RNa}_{\text {prox }}\right)$ may be calculated according to the formula: $\mathrm{RNa}_{\text {prox }}=100-\mathrm{FE}_{\mathrm{Li}}$ [27].

Samples for the measurements must be obtained in a way that excludes contamination with lithium from other sources. Moreover, a prerequisite for an accurate measurement is maintaining a stable diet without high-lithium and high-sodium products for 1-2 weeks before the collection of the samples, as well as avoiding drugs that may affect the investigated processes (unless they are being researched). High lithium levels have been found in certain mineral waters [28] and food products from regions with high environmental lithium levels [29].

The measurements of serum and urinary lithium concentrations on the level of biological background are currently not a routine method and must be performed in specialist laboratories. Several spectrophotometric methods, ensuring high sensitivity and appropriate precision, are used. These include: flame injection (FI-AAS) and graphite furnace-atomic absorption spectrometry (GF-AAS), inductively coupled plasma-atomic emission spectrometry (ICP-AES), and low- or high-resolution inductively coupled plasma-mass spectro- metry (ICP-MS). These methods require very small volume samples (of the order of $0.1 \mathrm{~mL}$ ) and their recent refinements allow for measurement of the collected samples either immediately [30, 31] or after minor preparation [32]. Their lower limit of detection is below $0.2 \mu \mathrm{g} / \mathrm{L}$, and precision is below $10 \%$. These methods are becoming increasingly available thanks to rapid technical progress and miniaturisation, resulting in lower costs of the analytical equipment.

\section{FACTORS DETERMINING RENAL METABOLISM OF SODIUM}

The processes of sodium excretion and reabsorption undergo a complex regulation in which several direct and indirect haemodynamic, genetic, hormonal, dietary and pharmacological factors are involved. Under physiological conditions, approximately $60-70 \%$ of sodium that has undergone filtration is reabsorbed on the level of proximal renal tubules, while as much as $90 \%$ of the remaining sodium load is reabsorbed in the distal portions of the nephron [33]. Numerous studies have demonstrated that reabsorption of sodium increases with age and is higher in males than in females [34], which was confirmed by the data obtained in large general population cohort (535 men vs. 534 women), in which significantly more effective sodium and lithium urinary excretion and higher $\mathrm{FE}_{\mathrm{Na}}$ values were demonstrated in males [35]. With respect to ethnic differences, a study including families of European and African ethnicity revealed that the African subjects had significantly higher sodium reabsorption than the European subjects. Moreover, ethnic differences were observed with respect to the location of increased sodium reabsorption in the nephron: in persons of African ethnicity, it was located in proximal tubules, while in persons of European ethnicity, reabsorption of sodium was relatively more pronounced in the distal portions of the nephron. It has also been revealed that the inheritance of both phenotypes of sodium reabsorption $\left(\mathrm{RNa}_{\text {prox }}\right.$ and $\left.\mathrm{RNa}_{\text {dist }}\right)$ is race-dependent [36]. In numerous studies, the association of overweight or obesity with increased reabsorption of sodium in proximal tubules was observed [35, $37,38]$. Increased sodium reabsorption is one of the initial pathological phenomena associated with the development of hypertension in obese persons [39]. Several hormones released by adipose tissue (like leptin) are able to stimulate reabsorption of sodium in renal tubules both directly and indirectly (via stimulation of sympathetic hyperactivity which is typical for obesity), while other mediators synthesised by adipose tissue (e.g. 2,13-epoxy-9-keto-10(trans)-octadecenoic acid [EKODE]) stimulate the secretion of aldosterone $[40,41]$. Moreover, adipocytes are an important source of angiotensinogen, which is the basis of the significant effect of adipose tissue (particularly visceral) on the renin-angiotensin-aldosterone (RAA) axis [42].

Among the hormonal factors, the leading role in this complex process is played by angiotensin II (Ang II). Kidneys 
contain many Ang II receptors, whose activation alters haemodynamics, glomerular permeability and urinary electrolyte excretion. It has been demonstrated that intravenous or intraarterial infusion of Ang II causes a decrease of renal flow and subsequent reduction of GFR due to vasoconstriction, including, among others, the afferent and efferent arterioles of the nephron. Moreover, Ang II has direct effects on the glomerulus, causing reduction of the ultrafiltration index and GFR. These mechanisms, together with the direct effects of Ang II on renal tubules, lead to increased sodium reabsorption in proximal tubules. Angiotensin converting enzyme (ACE) inhibitors have opposite effects. Numerous studies have revealed that they increase renal blood flow (this effect is more pronounced in subjects with high activity of the RAA system, which is physiological in persons consuming a low-sodium diet), maintain GFR and decrease both total and fractional sodium reabsorption [43]. With respect to the sartans, Burnier et al. [44] performed a detailed review of the effects of single-dose $100 \mathrm{mg}$ losartan vs. placebo on BP, haemodynamics and renal reabsorption of sodium (assessed using endogenous lithium clearance). The measurements were performed sequentially after six days of a high-sodium (200 mmol/day) and then a low-sodium (50 mmol/day) diet. In the losartan group, significant lowering of BP vs. placebo was observed, while there were no effects on GFR and renal blood flow, regardless of consuming a high-sodium or low-sodium diet. In the periods of consuming a low-sodium diet, significant elevations of plasma renin activity (PRA) and serum Ang II and alodosterone levels were observed. Moreover, the effects of losartan on the analysed parameters (i.e. significantly higher elevation of PRA and Ang II levels and decreased aldosterone levels) were higher than in patients on a high-sodium diet. Nevertheless, the most interesting results were obtained for the parameters of urinary water and electrolyte excretion. It was demonstrated that in persons consuming a low-sodium diet, the administration of losartan caused a statistically significant linear increase of 6-h urinary sodium excretion (up from 16.0 to $29.5 \mathrm{mmol}$ ), effectiveness of urinary sodium excretion (up from 115 to $207 \mu \mathrm{mol} / \mathrm{min}$ ), and fractional urinary sodium excretion (up from 0.76 to $1.48 \%$ ) compared to the values obtained before the administration of the drug. These trends were not observed in the placebo group. The spectrophotometrical measurements of endogenous lithium clearance revealed no differences in urinary lithium excretion rates, fractional lithium excretion or fractional proximal sodium reabsorption between the losartan and placebo groups, whereas a significant reduction of fractional distal sodium reabsorption was found in the losartan group. This may suggest that distal renal tubules are the part of the nephron in which ACE inhibitors and sartans directly exert their activity.

The results in the subjects consuming a high-sodium diet followed a trend similar to the group consuming a low-sodium diet, but they were much less apparent and did not reach statistical significance, thus suggesting a direct relationship between the RAA activity and the magnitude of the drug effect. Among other hormonal mechanisms of renal sodium reabsorption, much attention has been recently paid to the effects of dopamine which causes reduction of renal reabsorption of sodium mediated by $G$ protein-dependent stimulation of Type 1 dopamine receptors (DRD1) located in the proximal tubules $[27,45]$.

\section{ENDOGENOUS LITHIUM CLEARANCE AND THE PARAMETERS OF BLOOD PRESSURE, DAMAGE OF THE LARGE ARTERIES AND MYOCARDIAL REMODELLING}

Numerous observational studies conducted in the 1990s indicated an association between sodium turnover and elements of the RAA system and sodium-sensitivity of hypertension. All these studies were based on measurements of endogenous lithium clearance and they generally revealed a close relationship between increased sodium reabsorption in proximal renal tubules and hypertension. Fractional lithium excretion $\left(\mathrm{FE}_{\mathrm{Li}}\right)$ and calculated fractional proximal sodium reabsorption $\left(\mathrm{RNa}_{\text {prox }}\right)$ appeared to be markers of sodium sensitivity of hypertension independent of renal haemodynamics [26, 46]. Moreover, their predictive value for the development of hypertension [47] and relationship with the increase of cardiovascular risk [48] were demonstrated.

Among many studies covering this field, one - an Italian population study conducted within the Olivetti Heart Study project - became a breakthrough. The study included 47 healthy subjects consuming a high-sodium diet (average sodium intake $185 \mathrm{mmol} /$ day), in whom sodium in the diet was restricted to an average intake of $70 \mathrm{mmol} /$ day for three days. In the periods of consuming the high-sodium diet, $\mathrm{FE}_{\mathrm{Na}}$ values were significantly higher, while $R \mathrm{Na}_{\text {prox }}$ and $R \mathrm{Ra}_{\text {dist }}$ decreased significantly compared to the periods of consuming the low-sodium diet. However, most interesting were the results in subgroups divided into tertiles according to the decrease of mean arterial pressure caused by the reduction of the dietary sodium intake. These revealed that the patients in whom the fall of mean BP was most pronounced ( $\geq 9.6 \mathrm{~mm} \mathrm{Hg}$ vs. $9.6-3.9 \mathrm{mmHg}$ vs. $\leq 3.9 \mathrm{~mm} \mathrm{Hg}$ ) had the least pronounced reduction of $\mathrm{RNa}_{\text {prox }}$ caused by the changes of sodium consumption, which suggested a lack of flexibility of their sodium metabolism and a predisposition to the development of hypertension. Moreover, it revealed that a lack of adequate reduction of sodium reabsorption in proximal tubules was compensated for by a parallel increase of GFR [49]. These results were confirmed by another study by Chiolero et al. [50] including 38 patients with hypertension in whom the diet was changed from low-sodium (approximately $70 \mathrm{mmol} /$ day) to high-sodium by adding an extra $6 \mathrm{~g}$ of $\mathrm{NaCl} /$ day to the standard diet. The analyses included the tertiles of 'sodium-sensitivity' of hypertension based on the 
levels of reduction of mean arterial pressure resulting from dietary sodium restriction, with no reduction in the first tertile, $4 \mathrm{~mm} \mathrm{Hg}$ reduction in the second tertile, and $13 \mathrm{~mm} \mathrm{Hg}$ reduction in the third tertile. In the group of patients with the largest BP reductions after dietary sodium restriction, a decrease of $\mathrm{FE}_{\mathrm{Li}}$ values was observed, while in the first and third tertiles this parameter increased (third tertile from 24.7 to $19.5 \%$ vs. second tertile from 18.6 to $19.1 \%$ vs. first tertile from 17.0 to $23.0 \%$ ). The reverse correlation between the sodium load and $\mathrm{FE}_{\mathrm{Li}}$ in the third tertile that was found in this study indicated a significant role of sodium reabsorption in proximal tubules in this group of patients and confirmed the key role of $\mathrm{RNa}_{\text {prox }}$ in the pathogenesis of the sodium-sensitivity of hypertension. Notably, in both studies mentioned above, no relationship between $\mathrm{RNa}_{\text {dist }}$ and the sodium-sensitivity of hypertension was found, which was particularly reflected by a lack of compensatory $\mathrm{RNa}_{\text {dist }}$ decrease in patients with elevated $\mathrm{RNa}_{\text {prox }}$. In a recently published report, Zou et al. [51] analysed a large group of patients with untreated hypertension followed-up in China. Despite revealing no correlation of $\mathrm{FE}_{\mathrm{Li}}$ and $\mathrm{FDR}_{\mathrm{Na}}$ with BP parameters obtained both by conventional measurements and ambulatory BP monitoring in the whole study group, these authors observed significant correlation of daily dietary sodium intake and $\mathrm{FE}_{\mathrm{Li}}$ with respect to $\mathrm{BP}$ parameters, thus indicating a modulatory effect of dietary sodium intake on the balance of renal mechanisms of sodium regulation and $\mathrm{BP}$.

These very interesting studies may be the basis for an assumption that in patients with sodium-sensitive hypertension, we observe a paradoxical renal sodium retention in case of sodium overload and a tendency to increased sodium loss in case of its deficiency. This observation is extremely important in the context of an increasing problem of hyponatremia in the general population (including patients with hypertension and elderly persons) $[52,53]$. Perhaps the patients with sodium-sensitive hypertension may be particularly vulnerable to hypotension in cases of sodium restriction (especially when treated with diuretics causing high excretion of sodium). The uncontrolled episodes of hypotension resulting in organ hypoperfusion are presumed to be one of the important causes of ineffectiveness of an 'aggressive' antihypertensive treatment (aimed at achieving low target BP levels) seen in many randomised controlled trials. Perhaps this might also explain the reports on equivocal influence of sodium restriction on the prognosis in patients with hypertension [54].

However, when interpreting these studies one must bear in mind other mechanisms regulating the reabsorption of lithium, which might be of little importance in physiological conditions but may become apparent in 'extreme' situations. Vasopressin increases the reabsorption of lithium in the distal parts of the nephron; thus a major restriction of sodium causing hyponatremia, decrease of plasma osmolality and inhibition of $\mathrm{ADH}$ secretion may potentially increase the excretion of lithium due to the inhibition of its reabsorption in distal tubules, which leads to the underestimation of the actual reabsorption of sodium in proximal tubules [55].

In recent years, the team of scientists directed by Jan Staessen has published several papers on sodium sensitivity of hypertension and cardiovascular remodelling including the methodology of measurements using endogenous lithium clearance. Seidlerova et al. [35] in a paper published in the journal 'Hypertension' in 2006 analysed the relationship between various phenotypes of renal sodium turnover and BP and elastic properties of large arteries. The authors studied 1,069 untreated persons from the general population in whom they performed conventional BP measurements and ultrasonographic measurements of the diameter, compliance and distensibility of the brachial, femoral and carotid arteries. They found a correlation between selected parameters of stiffness and remodelling of muscular and elastic arteries and the $\mathrm{RNa}_{\text {prox }}$ and $\mathrm{RNa}_{\text {dist }}$ values. In another study, Jin et al. [56] analysed the relationship between sodium turnover and parameters of left ventricular hypertrophy. The study revealed an independent increase of the left ventricular mass index related to increased 24-h urinary sodium excretion. The authors also analysed the influence of elevated $\mathrm{RNa}_{\text {prox }}$ and $\mathrm{RNa}_{\text {dist }}$ on left ventricular mass index increase, but they found no statistically significant correlation of these parameters.

\section{LIMITATIONS OF THE METHOD}

Endogenous lithium clearance is currently regarded as the most accurate method of the assessment of renal sodium metabolism, although it has some limitations discussed in the literature.

The principal confounder that limits the use of this method, both in daily practice and research, is the influence of concomitant antihypertensive drugs, particularly diuretics and inhibitors of RAA. While the temporary discontinuation of diuretics for several days before the planned study in patients with well-controlled hypertension and no coexisting heart failure does not seem problematic in the majority of cases, the discontinuation of the RAA inhibitors may be controversial. Nevertheless, the results of the studies conducted to date suggest that in some situations, e.g. in patients with high dietary sodium consumption, it may be unnecessary. Burnier et al. [44] in the study mentioned above demonstrated a direct correlation of the activity of the RAA system (which is significantly reduced in patients consuming a high-sodium diet) and the magnitude of the effects of RAA inhibitors, which is significantly reduced in persons consuming a high-sodium diet. Moreover, Chiolero et al. [50] observed no differences of PRA and serum aldosterone levels in patients in the respective tertiles of sodium-sensitivity of hypertension, consuming either a low-sodium diet or (and particularly) a high-sodium diet. These results may indicate that the observed differences of $\mathrm{RNa}_{\text {prox }}$ between the tertiles are completely independent of the activity of the RAA system. 
Nevertheless, the effects of ACE inhibitors and sartans on $\mathrm{RNa}_{\text {dist }}$ values seem to be direct and unquestioned [44].

Another factor whose influence on the test results has been commonly implicated is a (minor) lithium reabsorption taking place also in the Henle's loop. The reabsorption in this part of the nephron is estimated at $7 \%$, which makes approximately one tenth of the reabsorbed lithium [22]. Nevertheless, the reabsorption of lithium in the distal tubules, which was observed in animal models, has not been confirmed in humans. The factors that may predispose to increased reabsorption of lithium beyond the proximal tubules include very low dietary sodium intake, low renal perfusion pressure, and altered vasopressin activity. Finally, it must be remembered that endogenous lithium clearance is an indirect measure of sodium reabsorption in renal tubules.

\section{CONCLUSIONS}

Numerous studies on animal models as well as epidemiological and clinical studies have demonstrated that in clinically stable patients endogenous lithium clearance is a reliable and repeatable tool for the assessment of renal sodium turnover. Currently, compared to all the available assays, endogenous lithium clearance is perceived as the most accurate method of the assessment of renal reabsorption of sodium, and its results directly reflect the GFR values. It also allows the avoidance of a measurement bias resulting from variable renal perfusion and incomplete 24-h urine collections [34].

The increasing number of publications on this method proves that endogenous lithium clearance is becoming an effective and widely available tool to be used in studies on the pathogenesis of primary hypertension and its target organ complications.

The present study was financially supported by a grant from the National Science Centre of Poland (Grant no.: N N 402 533239).

\section{Conflict of interest: none declared}

\section{References}

1. Zasady postępowania w nadciśnieniu tętniczym -2011 rok Wytyczne Polskiego Towarzystwa Nadciśnienia Tętniczego. Nadciśnienie Tętnicze, 2011; 4: 211-235.

2. Kurokawa K. Kidney, salt, and hypertension: how and why. Kidney Int, 1996; 55: S46-S51.

3. Intersalt: an international study of electrolyte excretion and blood pressure. Results of 24 hour urinary sodium and potassium excretion. Intersalt Cooperative Research Group. BMJ, 1988; 297: 319-328.

4. Denton D, Weisinger R, Mundy NI et al. The effect of increased salt intake on blood pressure of chimpanzees. Nat Med, 1995; 1: 1009-1016.

5. Stamler J, Rose G, Stamler R et al. INTERSALT study findings. Public health and medical card implications. Hypertension, 1989; 14: 570-577.

6. Safar ME. Systolic hypertension in the elderly: arterial wall mechanical properties and the renin-angiotensin-aldosterone system. J Hypertens, 2005; 23: 673-681.
7. du Cailar G, Mimran A, Fesler P et al. Dietary sodium and pulse pressure in normotensive and essential hypertensive subjects. J Hypertens, 2004; 22: 697-703.

8. Graudal NA, Galloe AM, Garred P. Effects of sodium restriction on blood pressure, renin, aldosterone, catecholamines, cholesterols, and triglyceride: a meta-analysis. JAMA, 1998; 279: 1383-1391.

9. Sacks FM, Svetkey LP, Vollmer WM et al. Effects on blood pressure of reduced dietary sodium and the Dietary Approaches to Stop Hypertension (DASH) diet. DASH-Sodium Collaborative Research Group. N Eng J Med, 2001; 344: 3-10.

10. Stevens VJ, Obarzanek E, Cook NR et al. Trials for the Hypertension Prevention Research Group. Long-term weight loss and changes in blood pressure: results of the Trials of Hypertension Prevention, phase II. Ann Intern Med, 2001; 134: 1-11.

11. Safar ME, Thuilliez C, Richard V, Benetos A. Pressure-independent contribution of sodium to large artery structure and function in hypertension. Cardiovasc Res, 2000; 46: 269-276.

12. Et-Taoui K, Schiavi P, Levy B, Plante G. Sodium intake, large artery stiffness, and proteoglycans in the spontaneously hypertensive rat. Hypertension, 2001: 38: 1172-1176.

13. Partovian C, Benetos A, Pommies JP et al. Effects of a chronic high-salt diet on large artery structure: role of endogenous bradykinin. Am J Physiol, 1998; 274: 1423-1428.

14. Levy BI, Poitevin P, Safar ME. Effect of indapamide on the mechanical properties of the arterial wall in deoxycorticosterone acetate-salt hypertensive rats. Am J Cardiol, 1990; 65: 28-32.

15. Avolio AP, Deng FQ, Li WQ et al. Effects of aging on arterial distensibility in populations with high and low prevalence of hypertension: comparison between urban and rural communities in China. Circulation, 1985; 71: 202-210.

16. Burnier M, Phan O, Wang Q. High salt intake: a cause of blood pressure-independent left ventricular hypertrophy? Nephrol Dial Transplant, 2007; 22: 2426-2429.

17. Langenfeld MR, Schobel H, Veelken R et al. Impact of dietary sodium intake on left ventricular diastolic filling in early essential hypertension. Eur Heart J, 1998; 19: 951-958.

18. Titze J, Machnik A. Sodium sensing in the interstitium and relationship to hypertension. Curr Opin Nephrol Hypertens, 2010; 19: 385-392.

19. Machnik A, Dahlmann A, Kopp C et al. Mononuclear phagocyte system depletion blocks interstitial tonicity-responsive enhancer binding protein/vascular endothelial growth factor $\mathrm{C}$ expression and induces salt-sensitive hypertension in rats. Hypertension, 2010; 55: 755-761.

20. Machnik A, Neuhofer W, Jantsch J et al. Macrophages regulate salt-dependent volume and blood pressure by a vascular endothelial growth factor-C-dependent buffering mechanism. Nat Med, 2009; 15: 545-552.

21. Luft FC, Fineberrg NS, Sloan RS. Estimating dietary sodium intake in individuals receiving a randomly fluctuating intake. Hypertension, 1982; 4: 805-808.

22. Koomans HA, Boer WH, Darhout Mees EJ. Evaluation of lithium clearance as a marker of proximal tubule sodium handling. Kidney Int, 1989; 36: 2-12.

23. Folkerd E, Singer DR, Cappuccio FP et al. Clearance of endogenous lithium in humans: altered dietary salt intake and comparison with exogenous lithium clearance. Am J Physiol, 1995; 268: F718-F722.

24. Leflon P, Plaquet R, Rose F et al. Rapid determination of lithium in human serum and urine, at physiological concentrations, by inductively coupled argon plasma atomic emission spectrometry. Analytica Chimica Acta, 1996; 327: 301-306.

25. Schrauzer GN. Lithium: occurrence, dietary intakes, nutritional essentiality. J Am Coll Nutr, 2002; 21: 14-21.

26. Burnier M, Biollaz J, Magnin JL et al. Renal sodium handling in patients with untreated hypertension and white coat hypertension. Hypertension, 1994; 3: 496-502. 
27. Staessen JA, Kuznetsova T, Zhang $\mathrm{H}$ et al. Blood pressure and renal sodium handling in relation to genetic variation in the DRD1 promoter and GRK4. Hypertension, 2008; 51: 1643-1650.

28. Fołta M, Bartoń H. Stężenie litu w wodach mineralnych oraz w wodach pitnych pobranych w domach mieszkańców Krakowa i obszaru Polski Południowej. Bromat Chem Toksykol, 2011; XLIV: 754-559.

29. Figueroa LT, Razmillic B, Zumeata O et al. Environmental lithium exposure in the north of Chile-II. Natural food sources. Biol Trace Elem Res, 2013; 151: 122-131.

30. Weder AB, Gleiberman L, Sachdeva A. Whites excrete a water load more rapidly than blacks. Hypertension, 2009; 53: 715-718.

31. Zhao J, Gao P, Wu S, Zhu D. Determination of trace lithium in human urine by electrothermal atomic absorption spectrometry using nitric acid as a chemical modifier to eliminate the interference of chloride. Anal Sci, 2009; 25: 639-643.

32. Zhao J, Gao P, Wu S, Zhu D. Superiority of nitric acid for deproteinization in the determination of trace lithium in serum by graphite furnace atomic absorption spectrometry. J Pharm Biomed Anal, 2009; 50: 1075-1079.

33. Burnier M, Bochud M, Maillard M. Proximal tubular function and salt sensitivity. Curr Hypertens Rep, 2006; 8: 8-15.

34. Strazzullo P, Galletti F, Barba G. Altered renal handling of sodium in human hypertension: short review of the evidence. Hypertension, 2003; 41: 1000-1005.

35. Seidlerová J, Staessen JA, Maillard M et al. Association between arterial properties and renal sodium handling in a general population. Hypertension, 2006; 48: 609-615.

36. Bochud M, Staessen JA, Maillard M et al. Ethnic differences in proximal and distal tubular sodium reabsorption are heritable in black and white populations. J Hypertens, 2009; 27: 606-612.

37. Strazzullo P, Barba G, Cappuccio FP et al. Altered renal sodium handling in men with abdominal adiposity: a link to hypertension. J Hypertens, 2001; 19: 2157-2164.

38. Venezia A, Barba G, Russo O et al. Dietary sodium intake in a sample of adult male population in southern Italy: results of the Olivetti Heart Study. Eur J Clin Nutr, 2010; 64: 518-524.

39. Kotsis V, Stabouli S, Papakatsika S et al. Mechanisms of obesity-induced hypertension. Hypertens Res, 2010; 33: 386-393.

40. Hall JE, da Silva AA, do Carmo JM et al. Obesity-induced hypertension: role of sympathetic nervous system, leptin, and melanocortins. J Biol Chem, 2010; 285: 17271-17276.

41. Goodfriend TL, Ball DL, Egan BM et al. Epoxy-keto derivative of linoleic acid stimulates aldosterone secretion. Hypertension, 2004; 43: 358-363.

42. Boscaro M, Giacchetti G, Ronconi V. Visceral adipose tissue: emerging role of gluco- and mineralocorticoid hormones in the setting of cardiometabolic alterations. Ann NY Acad Sci, 2012; 1264: 87-102.

43. Hollenberg NK, Meggs LG, Williams GH et al. Sodium intake and renal responses to captopril in normal man and in essential hypertension. Kidney Int, 1981; 20: 240-245.

44. Burnier M, Rutschmann B, Nussberger J et al. Salt-dependent renal effects of an angiotensin II antagonist in healthy subjects. Hypertension, 1993; 22: 339-347.

45. Felder RA, Jose PA. Mechanisms of disease: the role of GRK4 in the etiology of essential hypertension and salt sensitivity. Nat Clin Pract Nephrol, 2006; 2: 637-650.

46. Weder AB. Red-cell lithium-sodium countertransport and renal lithium clearance in hypertension. N Engl J Med, 1986; 314: 198-201.

47. Cappuccio FP, Strazzullo P, Farinaro E, Trevisan M. Uric acid metabolism and tubular sodium handling. Results from a population-based study. JAMA, 1993; 270: 354-359.

48. Cappuccio FP, Strazzullo P, Siani A, Trevisan M. Increased proximal sodium reabsorption is associated with increased cardiovascular risk in men. J Hypertens, 1996; 14: 909-914.

49. Barba G, Cappuccio FP, Russo L et al. Renal function and blood pressure response to dietary salt restriction in normotensive men. Hypertension, 1996; 27: 1160-1164.

50. Chiolero A, Maillard M, Nussberger J et al. Proximal sodium reabsorption: An independent determinant of blood pressure response to salt. Hypertension, 2000; 36: 631-637.

51. Zou J, Li Y, Chong-Huai Y et al. Blood pressure in relation to interactions between sodium dietary intake and renal handling. Hypertension, 2013; 62: 719-725.

52. Wald R, Jaber BL, Price LL et al. Impact of hospital-associated hyponatremia on selected outcomes. Arch Intern Med, 2010; 170: 294-302.

53. Waikar S, Mount DB, Curhan GC. Mortality after hospitalization with mild, moderate, and severe hyponatremia. Am J Med, 2009; 122: 857-865.

54. Stolarz-Skrzypek K, Kuznetsova T, Thijs Let al.; European Project on Genes in Hypertension (EPOGH) Investigators. Fatal and nonfatal outcomes, incidence of hypertension, and blood pressure changes in relation to urinary sodium excretion. JAMA, 2011; 305: 1777-1785.

55. Kirchner KA. Effect of antidiuretic hormone on lithium as a marker for proximal tubule delivery. Am J Physiol Renal Physiol,1989; 257: F899-F906.

56. Jin Y, Kuznetsova T, Maillard M et al. Independent relations of left ventricular structure with the 24-hour urinary excretion of sodium and aldosterone. Hypertension, 2009; 54: 489-495. 